\title{
INTERGENERIC HYBRIDISATION BETWEEN EREMOPYRUM ORIENTALE AND HENRARDIA PERSICA, AN EXAMPLE OF POLYPLOID SPECIES FORMATION*
}

\author{
SADAO SAKAMOTO \\ National Institute of Genetics, Misima, Japan
}

Received 5.iv.71

\section{Introduction}

The tribe Triticeae, Gramineae, includes about 14 genera. Among them Henrardia C. E. Hubbard represents a very small genus which contains two annual species, Hn. persica (Boiss.) C. E. Hubbard and Hn. pubescens (Bertol.) C. E. Hubbard (Hubbard, 1946). The chromosome numbers of both have been reported as $2 n=14$, for the former by Sakamoto and Muramatsu (1965) and for the latter by Bowden (1966). The two representatives have quite a characteristic morphology, different, according to Bor (1960), from other genera of the tribe by the following characters: spikelets 1-2-flowered, awnless, sunk into a jointed fragile spike-axis and closely appressed to it; florets enclosed in collateral glumes; lemmas thin, membranous, 3-5-nerved. Both species are distributed in Turkey (Anatolia) and from there have dispersed eastwards through Armenia and Transcaucasia to Russian Central Asia and southwards to Iraq, Iran, Afghanistan and Baluchistan (Hubbard, loc. cit.).

In an attempt to clarify the genetic relationships between this odd looking genus and other genera of the tribe, Hn. persica was crossed as either female or male parent with Aegilops bicornis Jaub. et Spach, Ae. caudata L., Ae. cylindrica Host, Ae. ovata L., Ae. sharonensis Eig, Ae. squarrosa L., Ae umbellulata Zhuk., Agropyron tsukushiense (Honda) Ohwi, Eremopyrum bonaepartis (Spreng.) Nevski, Er. orientale (L.) Jaub. et Spach, Heteranthelium piliferum (Banks et Sol.) Hochst, Taeniatherum asperum (Simonkai) Nevski and Triticum boeoticum Boiss. From these crosses intergeneric hybrids were obtained so far only in crosses of Henrardia persica with Eremopyrum orientale. The present report comprises cytogenetic studies of the hybridisation procedure which led to the formation of a new allohexaploid species arising from this combination.

\section{Materials and methods}

In the present successful intergeneric crosses, a strain of Eremopyrum orientale $(2 n=28$; strain no. 7037$)$ was used as the female parent and a strain of Henrardia persica var. glaberrima (Hausskn.) C. E. Hubbard $(2 n=14$; strain no. 7334) contributed the pollen. These two strains were collected at Ardabil-Tabriz, Iran, by the members of Kyoto University Scientific Expedition to the Karakoram and Hindukush in 1955 (Sakamoto and Muramatsu, 1965).

* Contribution no. 830 from the National Institute of Genetics, Misima, Japan. 
The crossing method was as follows. Two lowest florets of each spikelet of Er. orientale which served as the female parent were used in 1965 in a greenhouse. Hand-emasculated spikes were enclosed in paraffin-paper bags and were pollinated 2 days later by brushing the stigmas with newly broken anthers of $H n$. persica serving as the male parent. For the cytological observations the anthers were fixed in Farmer's solution ( 3 ethanol : 1 acetic acid) and stored in a refrigerator. Chromosome pairing was observed at MI of PMCs using the aceto-carmine squash technique. Microphotographs were taken from temporary preparations. In order to obtain amphiploids, 0.5 per cent. colchicine solution was applied to the basal parts of tillering clones of the hybrids using Sears' method (Sears, 1941).

Voucher specimens of the parental strains, the $F_{1}$ hybrid and the amphiploid were placed on file with the Royal Botanic Gardens, Kew, and the National Science Museum, Tokyo.

\section{Results}

From the pollination of 219 florets of Eremopyrum orientale with pollen of Henrardia persica 47 seeds were obtained. All were sown and gave seedlings, among them 25 true hybrids and 10 non-hybrids due to incomplete handemasculation.

\section{(a) Morphology of the parents and $F_{1}$ hybrids}

Several quantitative characters of the parents and the $F_{1}$ plants are listed in table 1. The average dates of first flowering of Er. orientale, Hn. persica and $F_{1}$ plants in the greenhouse were respectively 1st May, 1l th May and 30th April. Thus the $\mathrm{F}_{\mathbf{1}}$ plants started to bloom as early as the Eremopyrum parent.

TABLE 1

Quantitative characters

\section{Characters}

Average date of first flowering

No. of tillers

Culm length (cm.)

Length of top internode $(\mathrm{cm}$.)

Length of flag leaf $(\mathrm{cm}$.

Length of spike (cm.)

No. of spikelets per spike

Eremopyrum orientale
1st May
$56 \cdot 7$
$41 \cdot 3$
$16 \cdot 0$
$5 \cdot 3$
$3 \cdot 6$
$22 \cdot 8$

A marked heterotic increase in the number of tillers of the $F_{1}$ plants was observed, while the length of culms and spikes was intermediate between the parents. On the contrary, the length of the top internode and flag leaf and the number of spikelets per spike were similar to those of the Eremopyrum parent. The highest internode below the spike of the $F_{1}$ plants was puberulent like in Er. orientale.

As plate I, fig. a clearly shows, the spike shape of the $F_{I}$ was intermediate though clearly nearer to Eremopyrum, while the spikelets were distinctly of Eremopyrum type (plate I, fig. $b$ ). The glumes of Er. orientale are narrowly linear-acuminate, hispid, keeled and awned. Those of Hn. persica are broad, glabrous, keelless and awnless. The $\mathrm{F}_{1}$ glumes were of Eremopyrum type but the hairs were very short. The lemma of Er. orientale is narrowly ellipticacuminate as long as the glumes, indurated, hispidulous and shortly awned. 
Chromosome pairing of Eremopyrum orientale, Henrardia persica, their $\mathbf{F}_{1}$ hybrid and amphiploid and abnormal pollen formation of the $F_{1}(\times 750)$.

Frg. a.-Diakinesis of Er. orientale with 14 bivalents.

Frg. b.-Metaphase I of $\mathrm{Hn}$. persica with 7 bivalents.

Fig. c.-Metaphase $I$ of the $\mathbf{F}_{1}$ with 21 univalents. (Chromosome derived from Hn. persica are indicated by arrows.)

Fig. d.-Metaphase $I$ of the $F_{1}$ with one bivalent and 19 univalents.

Fig. e.-Metaphase $I$ of the $F_{1}$ with two bivalents and 17 univalents.

Fig. $f$.-Abnormal pollen formation of the $\mathbf{F}_{1}$.

Fig. g.-Metaphase I of the amphiploid with 21 bivalents.

FIG. h.-Metaphase I of the amphiploid with 20 bivalents and two univalents.

FIG. $i$.-Metaphase I of the amphiploid with 19 bivalents and four univalents. 


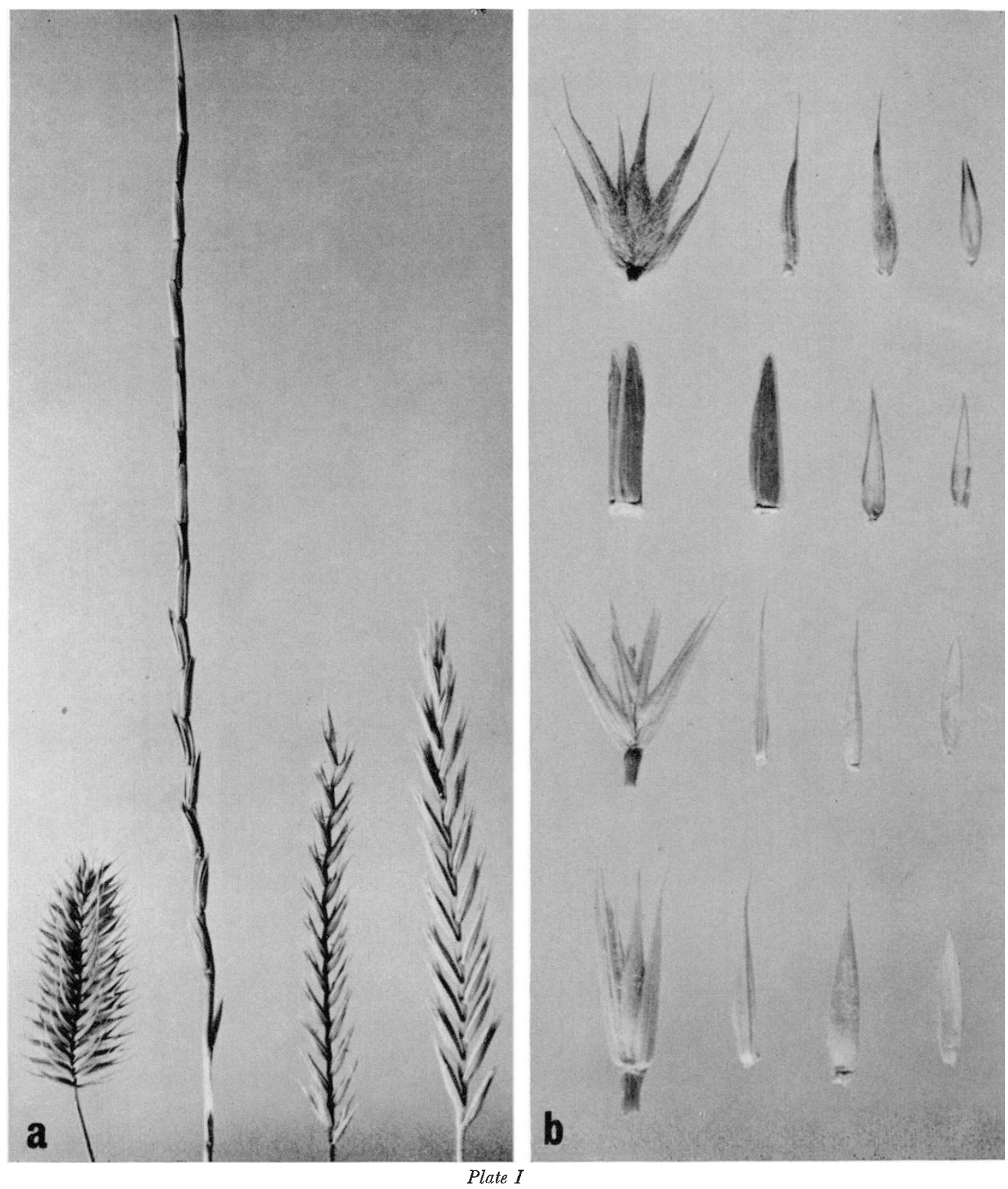

Fig. a.-Spikes. From left to right: Eremopyrum orientale, Henrardia persica, $\mathrm{F}_{1}$ hybrid, the amphiploid $(\times 0.85)$.

FIG. b.-Spikelet, glume, lemma and palea. From top downward: Eremopyrum orientale, Henrardia persica, $\mathrm{F}_{1}$ hybrid, the amphiploid $(\times 2 \cdot 5)$. 


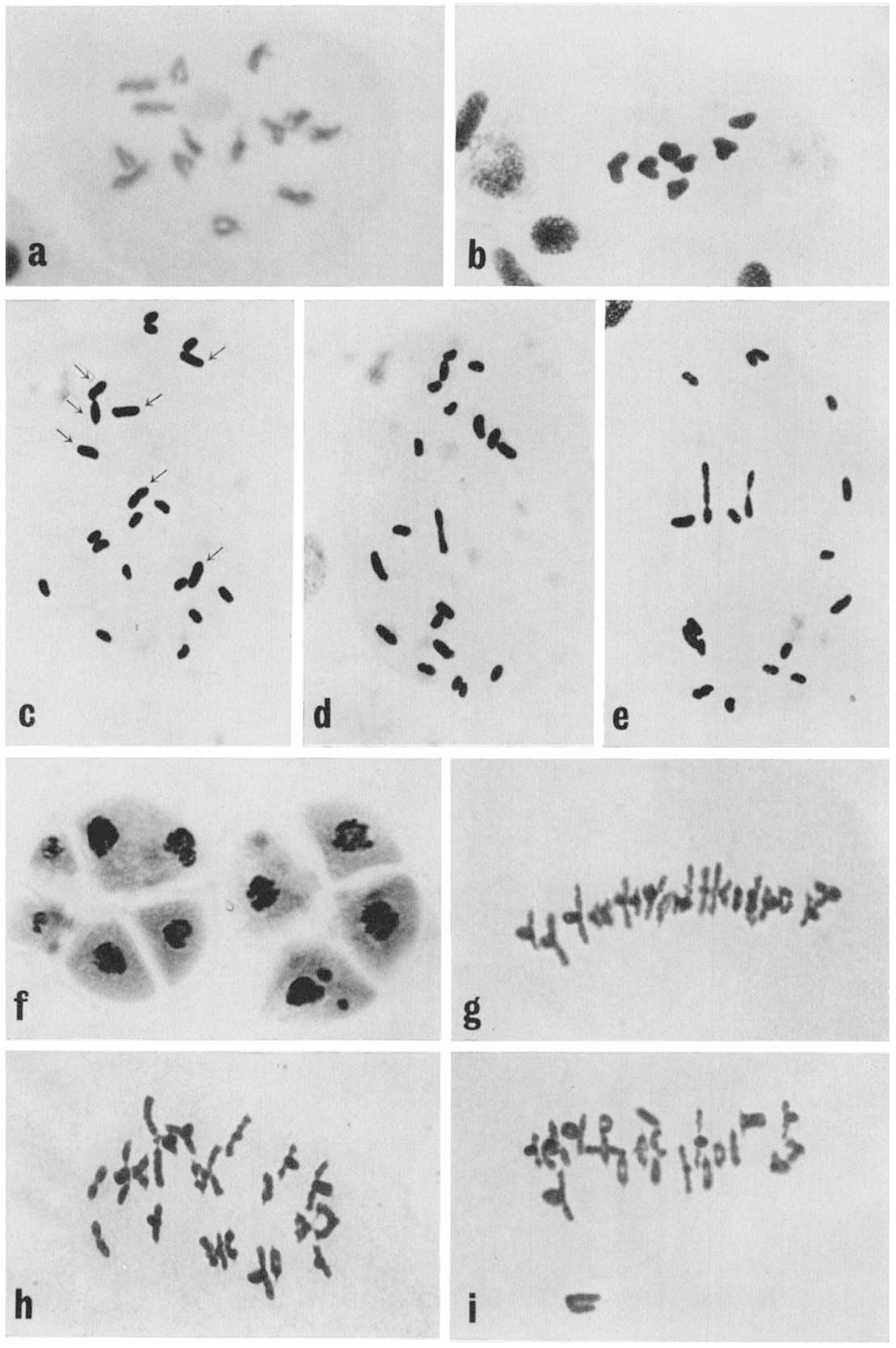


On the contrary, that of Hn. persica is broad, membranous, 3-5-nerved, glabrous and awnless. In the $\mathrm{F}_{1}$ the Eremopyrum type was predominant. The palea of Er. orientale is hard, 2-keeled and hairy between the keels while that of $\mathrm{Hn}$. persica is membranous, but also 2-keeled and hairy. The $\mathrm{F}_{\mathbf{1}}$ plants were intermediate between the parents (plate I, fig. $b$ ). Disarticulation of ripe spikelets of Er. orientale is of wedge-type, i.e. at every lower joint of the rachis. However, that of $H n$. persica is of barrel-type (i.e. brittle at every upper joint). The $\mathrm{F}_{1}$ showed the wedge-type disarticulation of the Eremopyrum parent.

(b) Cytology and fertility of $F_{1}$ hybrids

Chromosome pairing at MI of the parents, $F_{1}$ and amphiploids is listed in table 2 and plate II, figs. $a-i$. Of 2888 PMCs examined, 1894 (65.6 per

TABLE 2

Chromosome pairing at $M I$ of PMCs

\begin{tabular}{|c|c|c|c|c|}
\hline & Chror & som & airing & \\
\hline Strains & III & II & 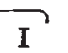 & $\begin{array}{l}\text { No. of cells } \\
\text { observed }\end{array}$ \\
\hline Parents & & & & \\
\hline Eremopyrum orientale & - & 14 & - & $42(100 \cdot 0 \%)$ \\
\hline Henrardia persica & - & 7 & - & $485(94 \cdot 8)$ \\
\hline & - & 6 & 2 & $26(5 \cdot 1)$ \\
\hline & - & 5 & 4 & $1(0 \cdot 1)$ \\
\hline Total & & & & 512 \\
\hline$F_{1}$ hybrid & - & 4 & 13 & $3(0.001)$ \\
\hline & - & 3 & 15 & $21(0.007)$ \\
\hline & - & 2 & 17 & $169(5.9)$ \\
\hline & 1 & 一 & 18 & $2(0.007)$ \\
\hline & - & 1 & 19 & $799(27 \cdot 7)$ \\
\hline & - & 一 & 21 & $1894(65.6)$ \\
\hline Total & & & & 2888 \\
\hline Amphiploid & - & 21 & - & $86(32 \cdot 8)$ \\
\hline & - & 20 & 2 & $99(37.8)$ \\
\hline & - & 19 & 4 & $48(18 \cdot 3)$ \\
\hline & - & 18 & 6 & $20(7 \cdot 6)$ \\
\hline & - & 17 & 8 & $6(2 \cdot 3)$ \\
\hline & - & 16 & 10 & $3(1 \cdot 1)$ \\
\hline Total & & & & 262 \\
\hline
\end{tabular}

cent.) showed 21 univalents (plate II, fig. c). One bivalent +19 univalents and two bivalents +17 univalents were found, respectively, in 799 (27.7 per cent.) and 169 (5.9 per cent.) cells. Cells with more than three bivalents were seldom observed. One trivalent was found in two cells only. Average chromosome pairing per PMC of the $\mathrm{F}_{1}$ showed 0.01 trivalent, 0.42 bivalent and $20 \cdot 20$ univalents. Bivalents ranging from one to four per cell were all terminally associated (plate II, figs. $d$ and $e$ ). Somatic chromosomes of Henrardia persica are larger than Eremopyrum's (Sakamoto and Muramatsu, 1965). Plate II, fig. $c$ clearly shows at MI of the $F_{1}$ seven larger univalents of $H n$. persica (indicated by arrows) and 14 smaller ones of Eremopyrum orientale. It is interesting that the seven larger chromosomes of Henrardia retain the same larger dimensions in the Eremopyrum cytoplasm, alien to them. 
Abnormal pollen formation in the $\mathrm{F}_{1}$ was often observed as shown in plate II, fig.f. 6030 pollen grains of $\mathrm{F}_{1}$ plants were examined. The majority were abortive and only 26 (0.44 per cent.) stained by diluted aceto-carmine. The anthers were non-dehiscent. Complete seed sterility was observed in self- and open-pollinated spikes.

\section{(c) The amphiploids}

Applying 0.5 per cent. colchicine solution to the basal parts of tillering clones of the $F_{1}, 150$ well-developed seeds were obtained from 67 spikes of four treated plants. Out of 62 seeds sown in 1966, 58 germinated normally and gave 52 vigorous amphiploid plants; six died before heading.

The morphological features of the colchicine-induced amphiploids were similar to those of the $F_{1}$ plants but most of the plant parts showed larger dimensions than the $\mathrm{F}_{1}$ (plate I, figs. $a$ and $b$ ). The average date of the first flowering in the greenhouse was 14th May. Disarticulation of the ripe spikelets was of wedge-type like in Er. orientale and in $\mathrm{F}_{1}$.

Chromosome pairing at MI of the PMCs of the amphiploids is shown in plate II, figs. $g-i$ and table 2 . Out of 262 cells, about one-third (32.8 per cent.) had 21 bivalents (plate II, fig. $g$ ), one-third ( 37.8 per cent.) showed 20 bivalents and two univalents and the remaining cells contained 16-19 bivalents per cell. No trivalent or higher association was found. Average chromosome pairing was 20.04 bivalents and 2.24 univalents per PMC. Of 2430 pollen grains examined 1839 were stainable. Therefore, pollen fertility was assessed at 75.7 per cent. Self- and open-pollinated seed fertilities were 48.3 per cent. and 81.4 per cent., respectively.

\section{Discussion}

In his taxonomical revision of taxa belonging to two very similar genera Lepturus and Pholiurus sensu Camus (1922), Hubbard (1946) recognised that two species of Pholiurus, Ph. persicus (Boiss.) A. Camus (= Lepturus persicus Boiss.) and Ph. pubescens (Bertol.) A. Camus (= Rottboellia pubescens Bertol.), had the following characters: ovary hairy at the apex, lodicule hairy, lemma three or more nerved and seed longitudinally grooved with simple starch grains in the endosperm. These characters have been regarded to be of diagnostic value in distinguishing the tribe Triticeae from other Gramineae tribes. On this basis Hubbard separated the two taxa from other Pholiurus taxa and established a new genus Henrardia C. E. Hubbard. The nomenclatural transfer was as follows: Henrardia persica (Boiss.) G. E. Hubbard and Hn. pubescens (Bertol.) C. E. Hubbard.

To elucidate the genetic relationships between the new genus Henrardia and other genera of the Triticeae tribe, the present author carried out extensive intergeneric crosses of Henrardia persica with Aegilops, Agropyron, Eremopyrum, Heteranthelium, Taeniatherum and Triticum. Among them only the hybrid between Eremopyrum orientale and Hn. persica succeeded. This result provided an important cytogenetic evidence for the correctness of Hubbard's taxonomical revision of the genus Henrardia and at the same time further strengthened the importance of intergeneric hybridisation as a reliable means for distinguishing the differences between morphological parallelism among unrelated taxa and morphological diversity among related ones. 
Grossability between Er. orientale and $\mathrm{Hn}$. persica was 11.4 per cent. calculating from the number of hybrid plants produced and number of florets pollinated. Although, as mentioned previously, the genus Henrardia due to its odd phenotypic traits is taxonomically quite distinct from other genera of the tribe Triticeae, the percentage of crossability shows indisputably a high genetic or may be mainly cytoplasmic compatibility between Eremopyrum and Henrardia.

As mentioned above, spike length of the $F_{1}$ plants was intermediate between the parents but clearly nearer to Eremopyrum and various parts of $\mathrm{F}_{1}$ spikelets were of Eremopyrum type as was observed also in Er. orientale $\times$ Aegilops squarrosa (Sakamoto, 1968). This may partly be the effect of the dosage, i.e. two genomes of Er. orientale vs. one genome of $\mathrm{Hn}$. persica or Ae. squarrosa in the $\mathrm{F}_{1}$ hybrids.

Lack of bivalent pairing in 66 per cent. of the $F_{1}$ PMCs, 0.42 bivalent per cell as the average in the $\mathrm{F}_{1}$ and high bivalent pairing, 20.04 per cell, of

TABLE 3

Average chromosome pairing and pollen- and seed-fertilities in three intergeneric $F_{1}$ hybrids and their amphiploids

\begin{tabular}{|c|c|c|c|c|c|c|}
\hline \multirow[b]{2}{*}{ Cross combinations $\left(q \times \sigma^{2}\right)$} & \multicolumn{4}{|c|}{ Average chromosome pairing } & \multirow{2}{*}{$\begin{array}{c}\text { Pollen } \\
\text { fertility (\%) }\end{array}$} & \multirow{2}{*}{$\begin{array}{c}\text { Seed } \\
\text { fertility }(\%)^{*}\end{array}$} \\
\hline & IV & III & II & I & & \\
\hline \multicolumn{7}{|c|}{ Eremopyrum orientale $(4 \times) \times$ Agropyron tsukushiense $(6 \times)$ : } \\
\hline$F_{2}(5 x)$ & - & - & 0.5 & $34 \cdot 0$ & 0.003 & 0 \\
\hline Amphiploid $(10 x)$ & 一 & - & $29 \cdot 4$ & $11 \cdot 2$ & $40 \cdot 2$ & $5 \cdot 5$ \\
\hline \multicolumn{7}{|c|}{ Eremopyrum orientale $(4 \times) \times$ Henrardia persica $(2 \times)$ : } \\
\hline$F_{1}(3 x)$ & - & $0 \cdot 0$ & 0.4 & $20 \cdot 2$ & $1 \cdot 0$ & 0 \\
\hline Amphiploid $(6 \times)$ & - & 一 & $20 \cdot 0$ & $2 \cdot 2$ & $75 \cdot 7$ & $48 \cdot 3$ \\
\hline \multicolumn{7}{|c|}{ Eremopyrum bonaepartis $(2 \times) \times$ Hordeum $\mathrm{sp} .(4 \times)$ : } \\
\hline$F_{1}(3 \times)$ & $0 \cdot 0$ & 0.0 & $5 \cdot 5$ & $10 \cdot 0$ & $1 \cdot 0$ & 0 \\
\hline Amphiploid $(6 x)$ & $0 \cdot 2$ & $0 \cdot 3$ & $17 \cdot 8$ & 4.9 & $56 \cdot 3$ & $34 \cdot 1$ \\
\hline
\end{tabular}

the amphiploids indicate the two genomes of Er. orientale and that of $\mathrm{Hn}$. persica are not homologous. Rare occurrence of trivalents in $F_{1}$, absence of multivalent association in $F_{1}$ as well as in the amphiploid, and formation of loosely connected terminally associated bivalents in $F_{1}$ also suggest lack of segmental homology among the chromosome complements of the three genomes of the two distantly related genera, two genomes of Eremopyrum and one of Henrardia.

From my cytogenetic studies of the genus Eremopyrum it is known that Er. orientale is an allotetraploid derived from amphidiploidisation between diploid Er. distans and diploid Er. triticeum (Sakamoto, 1967). Thus, the colchicine-induced hexaploid amphiploid plants have three different genomes $E r$. distans, Er. triticeum and Hn. persica respectively. The genera Eremopyrum and Henrardia are quite different from each other. The hybrid could be established only as an amphiploid. Similar amphiploids were recently produced in course of my study in two combinations of intergeneric hybridisation, i.e. Eremopyrum orientale $(2 n=28) \times$ Agropyron tsukushiense $(2 n=42)$ and Er. bonaepartis $(2 n=14) \times$ Hordeum sp. $(2 n=28)$ as shown 
in table 3 (Sakamoto, unpublished). In this table the average chromosome pairing at MI of PMCs and pollen- and seed-fertilities of the $F_{1}$ hybrids and their amphiploids are summarised. Low pollen- and seed-fertilities of the amphiploid between Er. orientale and $A g$. tsukushiense could be interpreted as the result of unexpected high frequency of univalent formation at MI. The average bivalent pairing, 5.5, observed in $\mathbf{F}_{\mathbf{1}}$ hybrid between diploid $E r$. bonaepartis and tetraploid Hordeum sp. indicate autosyndesis between chromosomes derived from the Hordeum parent. In these three amphiploids represented in table 3 quite different genomes were involved. In the first combination two genomes of Eremopyrum and three of Agropyron were involved. In the second two genomes of Eremopyrum and one of Henrardia and in the third case one genome of Eremopyrum and two of Hordeum were combined. However, all genomes could act as they do in Eremopyrum cytoplasm. Many intergeneric amphiploids in the tribe Triticeae were reported, for instance, such combinations as Agropyron $\times$ Hordeum, Elymus $\times$ Sitanion, Secale $\times$ Triticum, Triticum $\times$ Aegilops. In the cases described above, no disharmony could be observed between cytoplasm and introduced alien genomes. Even the larger size of Henrardia chromosomes was realised in the cytoplasm of Eremopyrum which has small chromosomes.

\section{Summary}

1. Henrardia is one of the very small genera in the tribe Triticeae represented by two annual species, $H n$. persica and $H n$. pubescens. Morphologically this genus is different from the other members of the tribe. In an attempt to clarify genetic relationships of this genus with other genera of the tribe, a strain of $H n$. persica var. glaberrima was crossed with various species of Aegilops, Agropyron, Eremopyrum, Heteranthelium, Taeniatherum and Triticum.

2. From these crosses $F_{1}$ hybrids were produced only when Er. orientale was used as the female parent. Morphological characters of the $F_{1}$ hybrids were of Eremopyrum type. Average chromosome sairing per PMC of the $\mathrm{F}_{\mathbf{1}}$ was 0.01 trivalent, 0.42 bivalent and 20.20 univalents. Bivalents ranging from one to four were all terminally associated. No genomic homology was found between $\mathrm{Er}$. orientale and $\mathrm{Hn}$. persica. Complete sterility was observed.

3. Applying 0.5 per cent. colchicine solution to the basal parts of tillering clones of the $F_{1}$, many well-developed seeds were obtained. From them vigorous amphiploids were grown. Average chromosome pairing per PMC of the amphiploids was 20.04 bivalents and 2.24 univalents. Pollen and self-pollinated seed fertilities were 75.5 per cent. and 48.3 per cent., respectively.

4. The successful production of those intergeneric hybrids provides important evidence for the correctness of Hubbard's (1946) taxonomical treatment of the genus Henrardia and at the same time further strengthens the importance of intergeneric hybridisation as a reliable means for distinguishing the differences between morphological parallelism among unrelated taxa and morphological diversity among related ones.

Acknowledgments.-The author wishes to thank Dr F. A. Lilienfeld, National Institute of Genetics, Misima, for her critical reading of the manuscript. Thanks are due also to Dr T. Tateoka, National Science Museum, Tokyo, for his kind suggestions regarding the taxonomy of the genus Henrardia. 


\section{REFERENCES}

BOR, N. L. 1960. Grasses of Burma, Ceylon, India and Pakistan. Pergamon Press, London. BoWDEN, w. M. 1966. Chromosome numbers in seven genera of the tribe Triticeae. Can. $\mathcal{J}$. Genet. Cytol., 8, 130-137.

camus, A. 1922. Note sur les Genres "Lepturus" R. Br. et "Pholiurus" Trinius. Ann. Soc. Linn. Lyon, 69, 86-90.

HUBbaRd, C. E. 1946. Henrardia, a new genus of the Gramineae. Blumea, Suppl. III, 10-21. SAKAMOto, s. 1967. Genome analysis of the genus Eremopyrum. Wheat Information Service, Nos. 23-24, 21-22.

sakamoto, s. 1968. Cytogenetic studies in the tribe Triticeae. VI. Intergeneric hybrid between Eremopyrum orientale and Aegilops squarrosa. Japan. 7. Genet., 43, 167-171.

SAKAMOTO, s., AND MURAMATsu, M. 1965. Morphological and cytological studies on various species of Gramineae collected in Pakistan, Afghanistan and Iran. In Results of the Kyoto University Scientific Expedition to the Karakoram and Hindukush, 1955, Vol. I, 119-140.

SEARs, E. R. 1941. Amphidiploids in the seven-chromosome Triticinae. Mo. Agri. Exp. Sta. Res. Bul., 336, 1-48. 